\title{
The relation between score on the stimulus variation scale and autokinetic movement
}

ROBERT C. REINEHR

UNIVERSITY OF TEXAS

\begin{abstract}
Score on a self-report inventory designed to measure the amount of stimulation seeking activity characteristically engaged in by adults (SVS) was related to performance in the autokinetic situation. A significant positive relationship between SVS score and amount of perceived movement was found when a simple linear measure was treated as the dependent variable. When Voth's MI was treated as the dependent variable results were in the hypothesized direction but failed of significance. Introduetion
\end{abstract}

A recent paper (Reinehr, 1965) reported the development of a self-report inventory purporting to measure the amount of stimulation seeking activity engaged in by adults. The Stimulus Variation Scale (SVS) was demonstrated to be reliable and to have some degree of discriminant validity.

Just as tests can be invalidated by high intercorrelations with tests which purport to measure different traits, some convergence of independent approaches is necessary for demonstration of construct validity. This sort of concurrent validation procedure may be employed for almost any test, by administering it to persons whose criterion performance can be observed immediately (Cronbach, 1960, P. 117)。

In the present study, performance on the stimulus variation scale (SVS) was related to autokinesis. The extent of perceived movement in the autokinetic situation can be converted to a quantitative value in a variety of ways. Voth (1947) used the following formula:

$$
\text { Index }=\sqrt{\frac{\mathrm{LxDC}}{\mathrm{S}+1}}
$$

where $\mathrm{L}=$ Length of Line, $\mathrm{DC}=$

Greatest Distance from Center, and $S=$ Stops.

This formula, known as Voth's Modified Index, or simply MI, is a satisfactorily stable response measure. Within a given subject, test-retest reliabilities a re consistently in the $.90^{\prime} \mathrm{s}$ when the same examiner and apparatus are used for both testings. Similar results have been found using a simple linear measure (LL) of the amount of movement perceived (Farrow, 1964).

Given the reliability of the autokinetic phenomenon, the question remaining is how performance in the autokinetic situation may be related to stimulus seeking behavior. The rationale is as follows: The light does not in fact move; any movement perceived must be a function of the unique perceptual processes of the individual. There is adequate evidence that individuals vary quite markedly in the amount of movement perceived and that a given individual tends to see the same amount of movement each time he is tested. It is thus hypothesized that individuals who perceive considerable movement in the autokinetic situation have different perceptual processes than individuals who see little movement and, further, that these differences are stable.

Berlyne (1960) suggests that curiosity motivation may be inferred from instrumental action or perceptual activity whose function is to increase the organism's contact with new or different environmental objects. Berlyne further suggests that these actions may be such as to increase the level or quantity of sensory input, and perception of movement in the autokinetic situation would seem to be activity of this sort. Smock \& Holt (1960) suggest that confrontation with environmental events that fail to match prevailing schemata evokes tendencies to develop new, or modify existing, perceptual cognitive structures by maximizing information input from environmental sources. They further suggest that this discrepancy between cognitive structure and environmental event processes constitutes the motivational basis for curiosity. Perception of movement in the autokinetic situation would appear to be activity which serves to reduce this discrepancy.

\section{Method \\ Sample}

Ss were 16 male and 16 female undergraduates from the University of Texas. Within each sex, $1 / 2$ of the Ss were drawn from the upper 25\% of a distribution of 138 SVS scores, and $1 / 2$ from the lower $25 \%$ of the same distribution.

Procedure

Ss were tested individually. Each was seated at a table $12 \mathrm{ft}$ away from a pin-point light in a totally dark room. Before him was a $22 \times 28$ in sheet of paper. $S$ was told that he would be leftalone in the darkened room for 10 min., during which time he was to focus on the light. It was explained that the light might or might not appear to move, that $\mathrm{E}$ was interested only in having S's personal response. Should the light appear to move, $\mathrm{S}$ was instructed to trace its' path on the paper with a pencil. Should the light stop, he was to make a small dot, leave his pencil poised there, and proceed to trace the light if it should appear to move again. Should the pencil reach the edge of the paper, S was to start from approximately the center of the paper and proceed as before. No suggestion was given that the light would actually move; Ss were merely told that it might or might not appear to move. The apparatus itself was never revealed to $\mathrm{S}$, a black curtain being drawn in front of itunless the room was darkened. Both LL and Voth's MI were recorded as response measures. 


\begin{tabular}{ccc}
\multicolumn{3}{c}{ TABLE I } \\
MEAN SVS, LL, AND MI SCORES FOR HIGH \\
AND LOW SVS GROUPS \\
Mean & Mean SVS & Mean LL \\
\hline High & 76.05 & 58.94 \\
Low & 42.65 & 30.75
\end{tabular}

\section{Results}

The means of the SVS scores of both groups, and the mean LL for each are presented in Table 1. A fixed analysis of variance revealed a significant difference in movement perceived when LL was used as a response measure $(F=7.22, p<.025)$, differences being in the hypothesized direction, i.e., Ss scoring high on the SVS perceived more movement. There were no differences when MI was used as the response measure. There were no differences due to sex of $S$ and there were no significant interactions with either measure.

\section{Discussion}

The relationsip between SVS score and perceived movement in the autokinetic situation is as hypothesized: Ss with high SVS scores report significantly more linear movement than do Ss with low SVS scores. This result obtains only when LL is used as the performance measure. When MI is used as the performance measure, differences are in the predicted direction but fail of significance.

The reason for these results to obtain only when the more simple linear measure is used is unclear. There are several possible explanations for the different results with different AK response measures. The ration- ale behind Voth's use of the MI measure is that this index affords better differentiation between psychiatric groups than does a simple linear method (Voth, 1941, 1947). Diagnostic power is of little interest in the present study, and a simpler index, affording a more direct measure of amount of movement pei-ceived, may be more appropriate. Voth \& Mayman (1963) suggest that a simpler measure would be more appropriate if one could be found which did not sacrifice predictive power for the sake of simplicity. They suggest LL as the simplest measure available. Thus, while MI may be the better index for psychiatric purposes, it may measure some variables unrelated to stimulation seeking. The present study involves a less complex prediction, and the less complex measure may be more appropriate.

\section{References}

Berlyne, D. E. Conflict, arousal, and curiosity. New York: McGrawHill, 1960 .

Cronbach, L. J. Essentials of psychological testing. New York, Evanston \& London: Harper \& Row, 1960.

Farrow, B. J. Unpublished manuscript, University of Texas, 1964.

Reinehr, R. C. A scale for the measurement of adult stimulation seeking behavior. J. Pers., submitted.

Smock, C. D., \& Holt, B. G. Children's reactions to novelty: an experimental study of "curiosity motivation." Child Develpm., 1962, 33, 631-642.

Voth, A. C. Individual differences in the autokinetic phenomenon. J. exp. Psychol., 1941, 29, 306-322.

Voth, A. C. An experimental study of mental patients through the autokinetic phenomenon. Amer. J. Psychiat., 1947, 103, 793-805. Voth, A. C., \& Mayman, M. Principles of personality organization Unpublished manuscript, Menninger Foundation, 1963.

\section{Note}

1. Now at Texas State Board for Hospitals and Special Schools, Austin, Texas. 